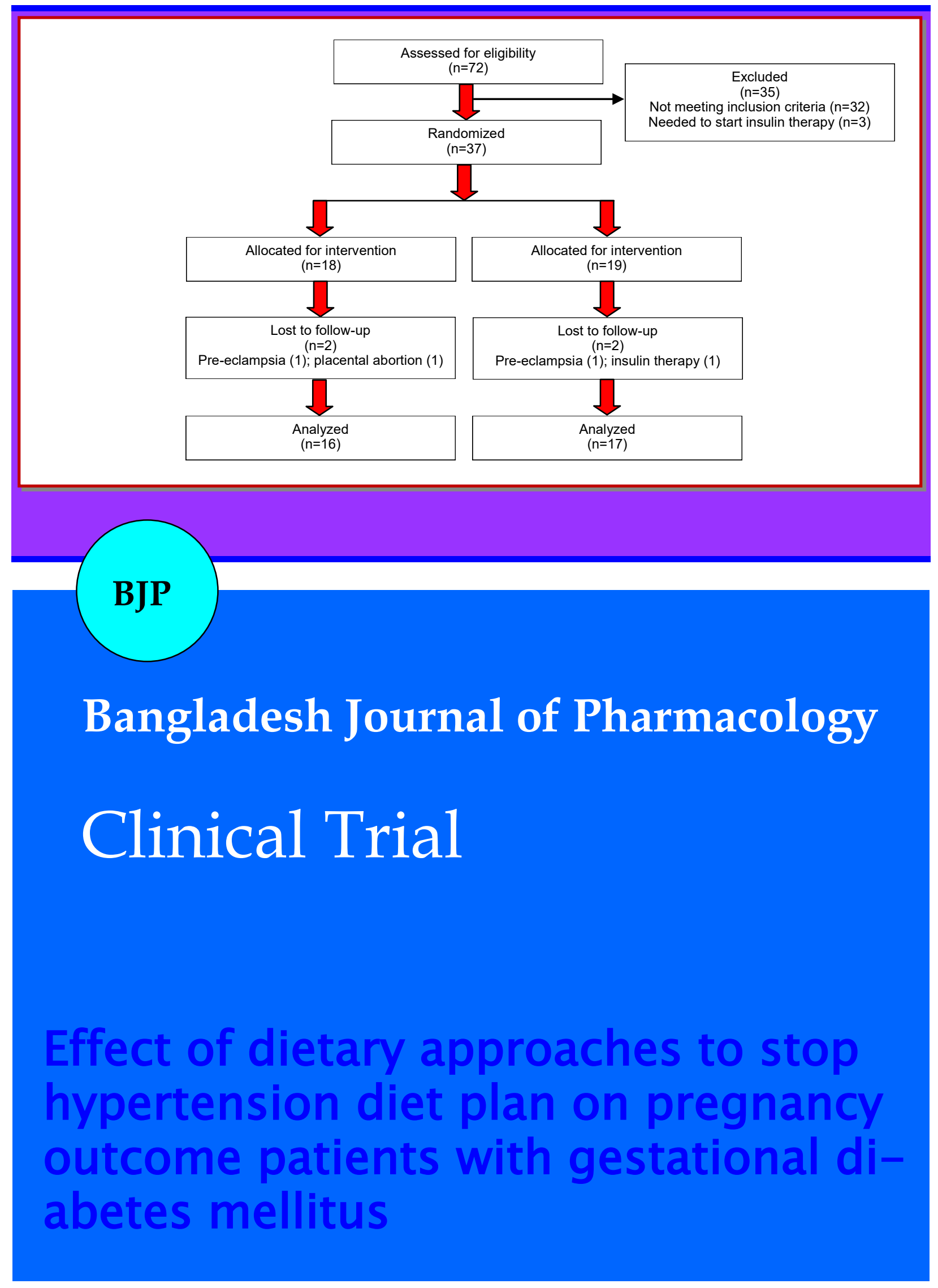




\title{
Effect of dietary approaches to stop hypertension diet plan on pregnancy outcome patients with gestational diabetes mellitus
}

\author{
Jie Yao, Lin Cong, Benli Zhu and Ting Wang
}

Department of Obstetrics and Gynecology, First Affiliated Hospital of Anhui Medical University, Hefei, Anhui 230 022, China.

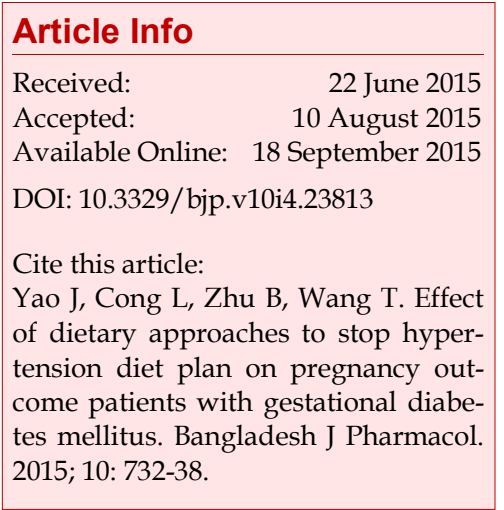

\begin{abstract}
The purpose of this study is to test the effects of Dietary Approaches to Stop Hypertension (DASH) diet plan on pregnancy outcomes patients with gestational diabetes mellitus. This randomized controlled clinical trial was performed among 33 women diagnosed with gestational diabetes. These patients were randomly distributed to the control group $(n=16)$ or DASH diet group $(n=17)$ for 4 weeks. Whereas $47.1 \%$ of women in the DASH diet needed to have a cesarean section, this percentage of mean gestational age in control diet was $81.3 \%(\mathrm{p}<0.01)$. Approximately $23.5 \%$ of women in the DASH diet and $75 \%$ of women in control diet needed to commence insulin therapy after intervention $(\mathrm{p}<0.01)$. In conclusion, the effect of DASH diet improved pregnancy outcomes patients with gestational diabetes.
\end{abstract}

\section{Introduction}

As a high-risk gestational disease, gestational diabetes mellitus is a common complication for pregnant women, with an incidence $1 \%$ to $5 \%$ (Asemi et al., 2014). It can lead to fetal macrosomia, which is the main effect on the fetus. At the same time, gestational diabetes can promote the increase in childbirth difficulty, and induce premature birth (Li et al., 2014). In addition, for pregnant women, gestational diabetes is the primary cause of ketoacidosis. So, if a puerpera suffers from gestational diabetes, with or without symptoms of diabetes mellitus, blood sugar must be effectively controlled, so that the safety of mother and child is fully guaranteed (Agarwal et al., 2015; Lai et al., 2014).

As a special type of diabetes mellitus, gestational diabetes has attracted people's attention. After the definite diagnosis of pregnancy, if there is a significant symptom of diabetes mellitus or reduced glucose tolerance, it can be diagnosed as gestational diabetes basically (Zhao et al., 2014). On all aspects of the management and treatment of patients with diabetes mellitus, nutritional therapy is necessary. Whether dependent or non-dependent, whether oral hypoglycemic agents or insulin injections, all must adhere to nutritional therapy. Blood glucose can be maintained within the normal range due to proper diet, which is one of the main treatment methods of patients with gestational diabetes (Levitan et al., 2009).

Meanwhile, diet control can be effective in alleviating the maternal complications such as gestational hypertension, post-partum infection, etc., and can also reduce the incidence of fetal complications such macrosomia. So that the nutritional needs of fetus and mother are met, to ensure good health and blood sugar levels can be maintained effectively in a stable state (Mann et al., 2014). However, the effect of Dietary Approaches to Stop Hypertension (DASH) diet on several metabolic conditions have been previously studied, there are no studies regarding the effects of DASH diet on insulin resistance, inflammation, oxidative stress, and pregnancy outcomes of pregnancy with gestational diabetes in China (Liao et al., 2014). Therefore, the aim of the research was to study the effect of DASH diet on pregnancy outcomes of patients with gestational diabetes in China. 


\section{Materials and Methods}

\section{Participants}

In First Affiliated Hospital of Anhui Medical University, between March 2014 and October 2014, the two-arm parallel unarranged trial in controlled condition for a clinical purpose was conducted. The weight at birth was defined as an important variable and grounded on previous studies, and the SD of this variable was set at $100 \pm 5 \mathrm{~g}$. In terms of average weight at birth between the two groups, we thought of $75 \mathrm{~g}$ as the significant difference. In consequence, the obligatory sample size was evaluated to be 21 participants in each and every group. Women of 18 to 40 years old, gravid for the first time and diagnostic of gestational diabetes by means of a 100-g oral glucose tolerance test during pregnancy for 24 to 28 weeks, were enlisted in this study. The age of pregnancy was evaluated from the date of last menstrual period and accompanying clinical evaluation. Women were pregnant but without a prior discovery of glucose intolerance, and were examined for gestational diabetes by way of two procedures. First of all, a $50 \mathrm{~g}$ glucose challenge test was carried out as initial investigation. Individual persons with 1-hour plasma glucose concentrations of $140 \mathrm{mg} / \mathrm{dL}$ were later required to undergo a test of $100 \mathrm{~g}$ oral glucose tolerance. Diagnosis of gestational diabetes was grounded upon the criteria as designed by the American Diabetes Association: people whose levels of plasma glucose corresponded with two of the following criteria were thought of as having gestational diabetes: fasting $>95 \mathrm{mg} / \mathrm{dL}, 1$-hour $\geq 180 \mathrm{mg} / \mathrm{dL}, 2$-hour $\geq 155$ $\mathrm{mg} / \mathrm{dL}$ and 3-hour $\geq 140 \mathrm{mg} / \mathrm{dL}$. Altogether, 72 pregnant women who went to maternity clinics subordinated to First Affiliated Hospital of Anhui Medical University, Anhui, China, were singled out for gestational diabetes. Women who were gravid in the aggregate were taken on in the study, and following classification of layers for pre-intervention body mass index (BMI; $<30$ and $\geq 30 \mathrm{~kg} / \mathrm{m}^{2}$ ) and weeks of pregnancy ( $<26$ or $\geq 26$ weeks), they were distributed to eat up the control $(n=16)$ or DASH diet $(n=17)$. Distribution was done at random by making use of random numbers produced by computer.

\section{Study design}

All the participants were assigned at random to eat up the control or DASH diet for four weeks on end. They were required not only to stick to their normal physical activities, but also to reject any antihyperglycemic or lipid-lowering medicines in the course of the intervention lasting four weeks. Every woman who was pregnant was taking in $400 \mathrm{mg}$ /day folic acid from the outset of gestation and $50 \mathrm{mg} /$ day ferrous sulfate as well as multivitamin-mineral supplements from 20 weeks of gestation. Conformity with the ingestion of diets was kept under observation once a week by means of phone interviews. Additionally, such conformity was checked more than once by the usage of threeday records in relation to diet which was finished throughout the entire study. The above-mentioned records were founded upon evaluated values obtained by way of household measurements. All the participants were obliged to conclude three one-day dietary records

\section{Diets}

The diet for the control group was contrived to include $45-55 \%$ carbohydrates, $15-20 \%$ protein and $25-30 \%$ total fat. The content of calorie and composition of the DASH diet in relation to protein corresponded with the control diet; nonetheless, the DASH diet was abundant in fruits, vegetables, whole grains and dairy products with low fat, and low in saturated fats, cholesterol, refined grains and sweets. The daily intake of sodium was 2,400 mg. The DASH diet founded on $2,000 \mathrm{kcal}$ is exemplified in Table I.

\begin{tabular}{|c|c|c|}
\hline \multicolumn{3}{|c|}{ Table I } \\
\hline \multicolumn{3}{|c|}{$\begin{array}{l}\text { Constituents of the control diets and DASH used in } \\
\text { the study }\end{array}$} \\
\hline Food group & Control diet $(n=16)$ & DASH $\operatorname{diet}(n=17)$ \\
\hline Grains & $11(68.8 \%)$ & $13(76.5 \%)$ \\
\hline Vegetables & $2(12.5 \%)$ & $1(5.9 \%)$ \\
\hline Fruits & $2(12.5 \%)$ & $2(11.8 \%)$ \\
\hline Else & $1(6.3 \%)$ & $1(5.9 \%)$ \\
\hline
\end{tabular}

\section{Assessment of maternal anthropometric measures}

Measurements of the size and proportions of pregnant women were evaluated at baseline and subsequent to four weeks of intervention by skilled midwives. The weight and height prior to pregnancy were extracted from the records of patients that existed in the clinic. At baseline and following four weeks of intervention, measurement of body weight was taken by means of a digital scale to the nearest $0.1 \mathrm{~kg}$ on an empty stomach without shoes in a minimal clothing state and measurement of height was performed with a non-stretched tape measure to the nearest $0.1 \mathrm{~cm}$. BMI was computed as weight in $\mathrm{kg}$ divided by height in meters squared.

\section{Assessment of pregnancy outcomes}

The intervention was made for no more than four weeks. All participants were kept under observation until delivery. They were rung up once every seven days to inquire whether they began to have insulin injected following intervention in relation to diet. For all participants, what was noted down included modes of delivery (cesarean section or vaginal delivery). Babies associated with gigantism were interpreted as those weighing $>4,000 \mathrm{~g}$ at birth. The perimeter of the head of each infant was measured to the nearest $1 \mathrm{~mm}$ by making use of a Seca girth measuring tape. The 5 
min Apgar score of the infants was also fixed as another measure of pregnancy outcome. The index of weight in relation to height $\left(\mathrm{kg} / \mathrm{m}^{3}\right)$ of the infant was worked out. The requirement for cesarean section in participants for the study was complied with by the study Obstetrician grounded upon estimated fetal weight, pelvic exam and other indications of cesarean section including malpresen-tation, fetal distress, dystocia and failure to progress of labor.

\section{Assessment of plasma glucose}

Blood samples on an empty stomach were collected at baseline at Kashan Reference Laboratory early in the morning after an overnight fasting. Levels of plasma glucose were quantified by making use of glucose oxidase/peroxidase (GOD-POD) method together with available kits on the market.

\section{Biochemical assessment}

At baseline and after 4 weeks of intervention, fasting blood samples $(10 \mathrm{~mL})$ were taken in the early morning at a Kashan Reference Laboratory. FPG levels were quantified by the use of glucose oxidase/peroxidase method with commercially available kits (Parsazmun Co, Iran). Serum insulin levels were measured using enzymelinked immunoassay (ELISA) kits (DiaMetra, Italy). Insulin resistance was assessed using the homeostatic model assessment of insulin resistance (HOMAIR) formula (Papandreou et al., 2004). Serum hs-CRP levels were quantified by ELISA method using available kits (LDN, Nordhorn, Germany). Plasma total antioxidant capacity (TAC) was assessed by means of the fluorescence recovery after photobleaching method developed by Benzie and Strain (Lewis et al., 2010).
Plasma GSH levels were measured using the method of Beutler et al (Kisters et al., 2006).

\section{Statistical analysis}

SPSS17.0 statistical software was use to data analysis. To ensure the normal distribution of variables, histogram and Kolmogorov-Smirnov tests were applied. We used independent samples Student's test to identify between-group differences. Carry out one-way ANOVA and determine the statistical significance using $\mathrm{p}<0.05$.

\section{Results}

\section{Summary of patient flow}

Figure 1 showed that the excluded patients of the DASH diet were two women (one pre-eclampsia and one insulin therapy). In the control diet, two women (one pre-eclampsia and one placenta abruption cases) were excluded. Finally, 33 participants [control $(\mathrm{n}=16)$ and DASH diet $(\mathrm{n}=17)$ ] completed the trial.

\section{General characteristics of the study participants}

Mean height, age, pre-pregnancy weight and BMI were not statistically different between the two groups (Table II). However, baseline weight and BMI as well as postintervention means of these changes in DASH group were very similar to those in the control group. Dietary intakes of study participants throughout the study: Based on the 3-day dietary records showed that there was no significant difference the terms of dietary intakes of energy between the two groups $(p=11$; Table III). However, significant differences were found in

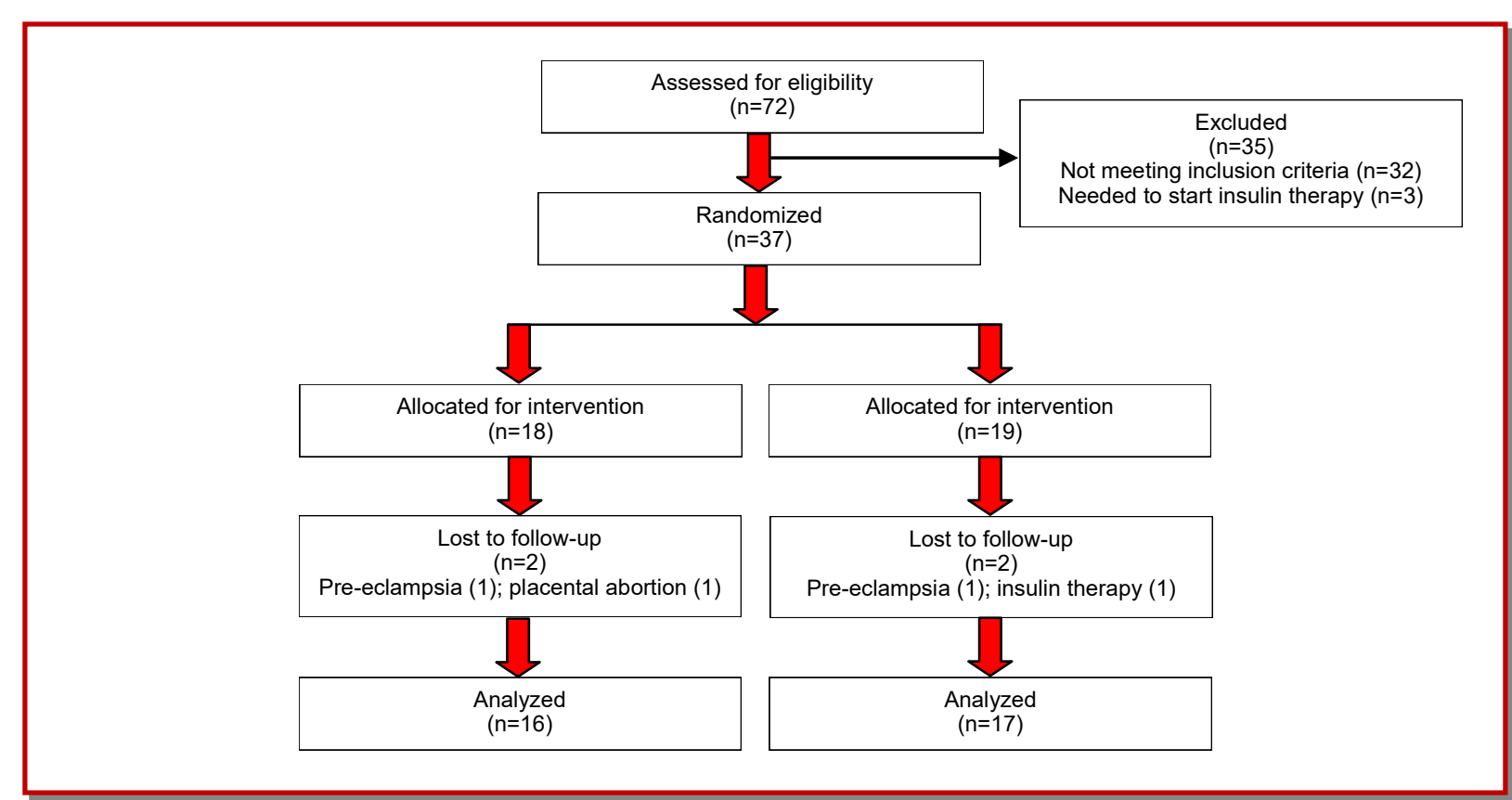

Figure 1: Summary of patient flow 
dietary intakes of fat, cholesterol, saturated fatty acids, polyunsaturated fatty acids, cholesterol, dietary fiber, simple sucrose, sodium, potassium, magnesium, calcium, fruits, vegetables and nuts between the two groups $(\mathrm{p}<0.01)$ (Table III).

\section{The effect of DASH diet on pregnancy outcomes}

The effect of DASH diet resulted in better pregnancy outcomes, compared with the control diet (Table IV). There were no significant inter-group difference between DASH diet and the control diet for mean gestational age (Table IV). Approximately $47.1 \%$ of women in the DASH diet needed to have a cesarean section, this percentage of mean gestational age in control diet was $81.3 \%(p<0.01)$. Meanwhile, $23.5 \%$ of women in the DASH diet and $75 \%$ of women in control diet needed to commence insulin therapy after intervention $(p<0.01)$. However, prevalence of polyhydramnios was not significantly different between the two groups. Macrosomia the DASH diet group was higher

\begin{tabular}{|c|c|c|c|}
\hline \multicolumn{4}{|c|}{ Table II } \\
\hline \multicolumn{4}{|c|}{ General characteristics of the study participants } \\
\hline & $\begin{array}{l}\text { Control diet } \\
\qquad(\mathrm{n}=16)\end{array}$ & $\begin{array}{l}\text { DASH diet } \\
\quad(\mathrm{n}=17)\end{array}$ & $\mathrm{p}$ value \\
\hline Height $(\mathrm{cm})$ & $160.3 \pm 5.7$ & $158.7 \pm 5.2$ & 0.2 \\
\hline Maternal age (years) & $28.3 \pm 5.1$ & $30.7 \pm 5.6$ & 0.3 \\
\hline Weight at study baseline (kg) & $78.3 \pm 6.3$ & $77.9 \pm 8.2$ & 0.8 \\
\hline Weight at end of trial (kg) & $80.7 \pm 7.6$ & $79.9 \pm 9.1$ & 0.6 \\
\hline Pre-pregnancy weight (kg) & $71.5 \pm 7.8$ & $70.7 \pm 6.1$ & 0.8 \\
\hline BMI at study baseline $\left(\mathrm{kg} / \mathrm{m}^{2}\right)$ & $30.9 \pm 3.6$ & $30.2 \pm 4.1$ & 0.7 \\
\hline BMI at end of trial $\left(\mathrm{kg} / \mathrm{m}^{2}\right)$ & $31.1 \pm 4.4$ & $30.8 \pm 5.3$ & 0.6 \\
\hline Pre-pregnancy BMI $\left(\mathrm{kg} / \mathrm{m}^{2}\right)$ & $29.6 \pm 5.3$ & $30.9 \pm 4.3$ & 0.8 \\
\hline $\mathrm{FPG}(\mathrm{mg} / \mathrm{dL})$ & $98.1 \pm 12.3$ & $97.9 \pm 14.2$ & 0.7 \\
\hline Gestational age (weeks) & $25.7 \pm 1.3$ & $26.9 \pm 1.4$ & 0.8 \\
\hline
\end{tabular}

DASH, Dietary Approaches to Stop Hypertension; BMI, body mass index; FPG, fasting plasma glucose

Table III

Dietary intakes of study participants throughout the study

\begin{tabular}{|c|c|c|c|}
\hline & Control diet & DASH diet & P value \\
\hline Energy (kcal/d) & $2386 \pm 174$ & $2408 \pm 54$ & 0.11 \\
\hline Fat $(g / d)$ & $75.1 \pm 13.4$ & $45.9 \pm 3.1$ & $<0.0001$ \\
\hline Protein $(\mathrm{g} / \mathrm{d})$ & $107.3 \pm 19.5$ & $101.5 \pm 7.3$ & 0.26 \\
\hline Carbohydrate (g/d) & $311.7 \pm 43.1$ & $401.3 \pm 14.1$ & $<0.0001$ \\
\hline $\operatorname{SFA}(g / d)$ & $20.3 \pm 3.7$ & $9.3 \pm 0.9$ & $<0.0001$ \\
\hline PUFA (g/d) & $27.8 \pm 0.8$ & $12.9 \pm 1.7$ & $<0.0001$ \\
\hline Cholesterol (mg/d) & $257.5 \pm 168.1$ & $103.3 \pm 26.4$ & $<0.0001$ \\
\hline Dietary fiber (g/d) & $17.2 \pm 2.1$ & $23.3 \pm 1.4$ & $<0.0001$ \\
\hline Simple sucrose (g/d) & $23.1 \pm 11.1$ & $14.1 \pm 2.5$ & $<0.0001$ \\
\hline Sodium (mg/d) & $3878.7 \pm 411.6$ & $1418.3 \pm 188.4$ & $<0.0001$ \\
\hline Potassium (mg/d) & $2612.7 \pm 311.9$ & $4231.9 \pm 91.2$ & $<0.0001$ \\
\hline Magnesium (mg/d) & $256.7 \pm 46.1$ & $371.1 \pm 17$ & $<0.0001$ \\
\hline Calcium (mg/d) & $1036.8 \pm 207.1$ & $1815.4 \pm 7$ & $<0.0001$ \\
\hline Fruits (servings/d) & $4.1 \pm 1.1$ & $6.3 \pm 0.7$ & $<0.0001$ \\
\hline Vegetables (servings/d) & $4.3 \pm 1.2$ & $6.1 \pm 0.7$ & $<0.0001$ \\
\hline Nuts (servings/d) & $0.3 \pm 0.1$ & $2.2 \pm 0.4$ & $<0.0001$ \\
\hline
\end{tabular}

DASH, Dietary Approaches to Stop Hypertension; SFA, saturated fatty acids; PUFA, polyunsaturated fatty acids 
than that of control diet group (6 versus $1, \mathrm{p}<0.001$ ) (Table IV).

\section{Effect of DASH diet on birth size of the newborns}

The effect of DASH diet brought about a significant reduction in the birth of length (50.3 versus $51.8 \mathrm{~cm}, \mathrm{p}=$ $0.25)$, weight (3.2 versus $3.8 \mathrm{~kg}, \mathrm{p}<0.0001)$, head circumference (34.0 versus $35.3 \mathrm{~cm}, \mathrm{p}<0.01)$ and ponderal index $\left(2.5\right.$ versus $\left.2.9 \mathrm{~kg} / \mathrm{m}^{3}, \mathrm{p}<0.01\right)$, compared with these changes of the control diet (Table V). However, in Apgar score, no significant changes amongst between the two diets were seen (Table V).

Effect of DASH diet on FPG, insulin, HOMA-IR, hsCRP and stress oxidative

The effect of the DASH diet compared with the control diet resulted in reduced fasting plasma glucose $(-8.1$ versus $3.8 \mathrm{mg} / \mathrm{dL}, \mathrm{p}=0.01)$, serum insulin levels $(-2.5$ versus $4.3 \mu \mathrm{IU} / \mathrm{mL}, \mathrm{p}=0.02)$, HOMA-IR score $(-0.7$ versus $1.2, \mathrm{p}=0.02)$, total antioxidant capacity (48.1 versus $-152.5 \mathrm{mmol} / \mathrm{L}, \mathrm{p}<0.01$ ), and total glutathione (109.5 versus $-155.3 \mu \mathrm{mol} / \mathrm{L}, \mathrm{p}<0.01$ ) (Table VI). But, there was no significant difference the mean changes of serum hs-CRP levels between the DASH diet and the control diet (Table VI). Within-group changes of fasting plasma glucose and serum insulin levels showed a significant promotion in the control diet, but a significant decrease in the DASH diet (Table VI). Meanwhile, the plasma TAC and GSH levels showed a significant reduction in the control diet, the DASH diet reversed these changes (Table VI).

\section{Discussion}

Our findings showed that the effect of DASH diet in pregnant women with gestational diabetes had beneficial effects on rate of cesarean section, need to commence insulin, FPG, serum insulin levels, HOMAIR score, and biomarkers of oxidative stress. In the DASH diet group, mean weight, head circumference and ponderal index of infants born to mothers were significantly decreased compared with those of born to mothers in the control diet. To our knowledge, this study is the first reporting the effect of DASH diet on pregnancy outcomes patients with gestational diabetes in China.

The possible mechanisms underlying the association between these nutriment and increased risk of cesarean section remain largely obscure. In the control group, higher rate of cesarean section might be attributed to maternal hypertension at the end pregnancy.

On all aspects of the management and treatment of patients with diabetes mellitus, nutritional therapy plays a very necessary role (Huynh et al., 2015). Whether dependent or non-dependent, whether oral hypoglycemic agents or insulin injections, all must adhere to nutritional therapy (Nowson et al., 2009). Blood glucose can be maintained within the normal range due to proper diet, which is one of the main treatment methods of patients with gestational diabetes (Saneei et al., 2014). Nutrition therapy has more important effect on gestational diabetes patients.

\section{Table IV}

Effect of DASH diet on pregnancy outcomes

\begin{tabular}{|lrr|r|} 
& $\begin{array}{c}\text { Control diet } \\
(\mathrm{n}=16)\end{array}$ & \multicolumn{1}{c}{$\begin{array}{c}\text { DASH diet } \\
(\mathrm{n}=17)\end{array}$} & \multicolumn{1}{c|}{ value } \\
\hline Gestational age (weeks) & $37.9 \pm 1.5$ & $38.5 \pm 1.3$ & $<0.01$ \\
Cesarean section (\%) & $13(81.3)$ & $8(47.1)$ & $<0.0001$ \\
Need for insulin therapy after intervention (\%) & $12(75)$ & $4(23.5)$ & 0.38 \\
Polyhydramnios (\%) & $1(6.3)$ & $1(5.9)$ & $<0.001$ \\
Macrosomia (birth weight $>4000 \mathrm{~g})(\%)$ & $6(37.5)$ & 0.01 & \\
\hline
\end{tabular}

Table V

Effect of DASH diet on birth size of the newborns

\begin{tabular}{|lrrr|} 
& Control diet & DASH diet & p value \\
\hline Newborn length $(\mathrm{cm})$ & $51.8 \pm 0.4$ & $50.3 \pm 0.4$ & 0.25 \\
Newborn weight $(\mathrm{kg})$ & $3.8 \pm 0.1$ & $3.2 \pm 0.1$ & $<0.0001$ \\
Newborn head $(\mathrm{cm})$ & $35.3 \pm 0.2$ & $34.0 \pm 0.1$ & $<0.01$ \\
Ponderal index $\left(\mathrm{kg} / \mathrm{m}^{3}\right)$ & $2.9 \pm 0.1$ & $2.47 \pm 0.1$ & $<0.0001$ \\
Apgar score & $10.0 \pm 0.0$ & $9.97 \pm 0.0$ & 0.61 \\
\hline
\end{tabular}


Table VI

Effect of DASH diet on FPG, insulin, HOMA-IR, hs-CRP and stress oxidative

\begin{tabular}{|lcrr|}
\hline & $\begin{array}{c}\text { Control diet } \\
(\mathrm{n}=16)\end{array}$ & $\begin{array}{c}\text { DASH diet } \\
(\mathrm{n}=17)\end{array}$ & p value \\
\hline Fasting plasma glucose $(\mathrm{mg} / \mathrm{dL})$ & $3.7 \pm 4.7$ & $-8.1 \pm 2.3$ & 0.01 \\
Insulin $(\mu \mathrm{IU} / \mathrm{mL})$ & $4.3 \pm 2.4$ & $-2.5 \pm 1.8$ & 0.02 \\
HOMA-IR & $1.2 \pm 0.8$ & $-0.7 \pm 0.5$ & 0.02 \\
hs-CRP $(\mathrm{ng} / \mathrm{mL})$ & $163.2 \pm 792.6$ & $348.3 \pm 588.8$ & 0.76 \\
Total antioxidant capacity $(\mathrm{mmol} / \mathrm{L})$ & $-152.5 \pm 41.5$ & $48.1 \pm 14.8$ & $<0.0001$ \\
Total glutathione $(\mu \mathrm{mol} / \mathrm{L})$ & $-155.3 \pm 46.8$ & $109.5 \pm 39.7$ & $<0.0001$ \\
\hline
\end{tabular}

DASH, Dietary Approaches to Stop Hypertension; HOMA-IR, Homeostasis Model of Assessment Insulin Resistance; hs-CRP, high -sensitivity C-reactive protein

Nutritional therapy and diet therapy for the patients with gestational diabetes need recurrent fasting blood glucose monitoring, so that blood sugar levels in patients with gestational diabetes can be maintained at 4.4 6.7 mmol/L, while gestational diabetes patients need to maintain blood glucose lower than $8.3 \mathrm{mmol} / \mathrm{L}$ 1 hour after meal (Young et al., 2008). According to the discussion from relevant literature, in the calculation of the total calories needed by pregnant women each day, the standard weight of pregnant women must be taken as basic weight, and then pregnant women need the total calories $167 \mathrm{KJ}$ multiplied by weight (Moss et al., 2007). If the weight of a pregnant woman is within the scope of normal weight, which is $80 \%$ to $120 \%$ of the normal standard weight, this pregnant woman needs totally $126 \mathrm{KJ}$ calories per kilogram of body weight each day (Scioscia et al., 2007). If a pregnant woman is outside the scope of high weight, which is more than $120 \%$ of the standard weight, then she needs totally 100 KJ calories per kilogram of body weight each day, in which carbohydrates account for roughly $30 \%$ to $40 \%$ of total calories (Gunther et al., 2009). At the same time, $1.5 \mathrm{~g} / \mathrm{kg}$ of protein intake should be guaranteed everyday (D'Anna et al., 2007). In the current study, cesarean section, needed to commence insulin therapy and macrosomia of women in the DASH diet were observably higher than those of control diet group. Meanwhile, in the birth of weight, head circumference and ponderal index in the DASH diet were markedly greater than those of these changes of the control diet.

\section{Conclusion}

The effect of DASH diet for 4 weeks improved insulin resistance, inflammation, oxidative stress, and pregnancy outcomes of patients with gestational diabetes

\section{Ethical Issue}

The study was carried out in accordance with the guidelines drawn up in the Declaration of Helsinki. The ethical committee of the First Affiliated Hospital of Anhui Medical University consented to the study and informed written consent was acquired from each and every participant.

\section{References}

Agarwal MM, Shah SM, Al Kaabi J, Saquib S, Othman Y. Gestational diabetes mellitus: Confusion among medical doctors caused by multiple international criteria. J Obstet Gynaecol Res. 2015; 41: 861-69.

Asemi Z, Samimi M, Tabassi Z, Esmaillzadeh A. The effect of DASH diet on pregnancy outcomes in gestational diabetes: A randomized controlled clinical trial. Eur J Clin Nutr. 2014; $68 ; 490-95$.

Asemi Z, Samimi M, Tabassi Z, Sabihi SS, Esmaillzadeh A. A randomized controlled clinical trial investigating the effect of DASH diet on insulin resistance, inflammation, and oxidative stress in gestational diabetes. Nutrition 2013; 29; 619-24.

D'Anna R, Baviera G, Cannata ML, De Vivo A, Di Benedetto A, Corrado F. Midtrimester amniotic fluid leptin and insulin levels and subsequent gestational diabetes. Gynecol Obstet Invest. 2007; 64; 65-68.

Gunther AL, Liese AD, Bell RA, Dabelea D, Lawrence JM, Rodriguez BL, Standiford DA, Mayer-Davis EJ. Association between the dietary approaches to hypertension diet and hypertension in youth with diabetes mellitus. Hypertension 2009; 53: 6-12.

Huynh J, Dawson D, Roberts D, Bentley-Lewis R. A systematic review of placental pathology in maternal diabetes mellitus. Placenta 2015; 36: 101-14.

Kisters K, Gremmler B, Hausberg M. Preventing pregnancyinduced hypertension: The role of calcium and magnesium. J Hypertens. 2006; 24, 201; Author reply 2.

Lai FY, Johnson JA, Dover D, Kaul P. Outcomes of singleton and twin pregnancies complicated by preexisting diabetes and gestational diabetes: A population-based study in Alberta, Canada, 2005-2011. J Diabetes. 2014.

Levitan EB, Wolk A, Mittleman MA. Relation of consistency with the dietary approaches to stop hypertension diet and incidence of heart failure in men aged 45 to 79 years. Am J 
Cardiol. 2009; 104: 1416-20.

Lewis S, Lucas RM, Halliday J, Ponsonby AL. Vitamin D deficiency and pregnancy: From preconception to birth. Mol Nutr Food Res. 2010; 54; 1092-102.

Li J, Zhu Q, Wang H, Han C, Zhou Q, Huang H, Dong M. Decreased fetal pre-adipocyte factor-1 in pregnancies complicated by gestational diabetes mellitus. Clin Chim Acta. 2014; 431: 93-95.

Liao S, Mei J, Song W, Liu Y, Tan YD, Chi S, Li P, Chen X, Deng S. The impact of the International Association of Diabetes and Pregnancy Study Groups (IADPSG) fasting glucose diagnostic criterion on the prevalence and outcomes of gestational diabetes mellitus in Han Chinese women. Diabetic Med. 2014; 31: 341-51.

Mann DM, Quintiliani LM, Reddy S, Kitos NR, Weng M. Dietary Approaches to Stop Hypertension: Lessons learned from a case study on the development of an mHealth behavior change system. JMIR Mhealth Uhealth. 2014; 2: e41.

Moss JR, Crowther CA, Hiller JE, Willson KJ, Robinson JS. Costs and consequences of treatment for mild gestational diabetes mellitus: Evaluation from the ACHOIS randomised trial. BMC Pregnancy Childbirth. 2007; 7: 27.

Nowson CA, Wattanapenpaiboon N, Pachett A. Low-sodium Dietary Approaches to Stop Hypertension-type diet including lean red meat lowers blood pressure in postmenopausal women. Nutr Res. 2009; 29; 8-18.
Papandreou L, Chasiotis G, Seferiadis K, Thanasoulias NC, Dousias V, Tsanadis G, Stefos T. Calcium levels during the initiation of labor. Eur J Obstet Gynecol Reprod Biol. 2004; 115: 17-22.

Saneei P, Salehi-Abargouei A, Esmaillzadeh A, Azadbakht L. Influence of Dietary Approaches to Stop Hypertension (DASH) diet on blood pressure: A systematic review and meta-analysis on randomized controlled trials. Nutr Metab Cardiovasc Dis. 2014; 24: 1253-61.

Scioscia M, Kunjara S, Gumaa K, McLean P, Rodeck CH, Rademacher TW. Urinary excretion of inositol phosphoglycan P-type in gestational diabetes mellitus. Diabetic Med. 2007; 24: 1300-04.

Xie BG, Jin S, Zhu WJ. Expression of toll-like receptor 4 in maternal monocytes of patients with gestational diabetes mellitus. Exp Ther Med. 2014; 7: 236-40.

Xin G, Du J, Wang YT, Liang TT. Effect of oxidative stress on heme oxygenase-1 expression in patients with gestational diabetes mellitus. Exp Ther Med. 2014; 7: 478-82.

Young CM, Batch BC, Svetkey LP. Effect of socioeconomic status on food availability and cost of the Dietary Approaches to Stop Hypertension (DASH) dietary pattern. J Clin Hypertens (Greenwich). 2008; 10: 603-11.

Zhao C, Zhang T, Shi Z, Ding H, Ling X. MicroRNA-518d regulates PPAR alpha protein expression in the placentas of females with gestational diabetes mellitus. Mol Med Rep. 2014; 9; 2085-90.

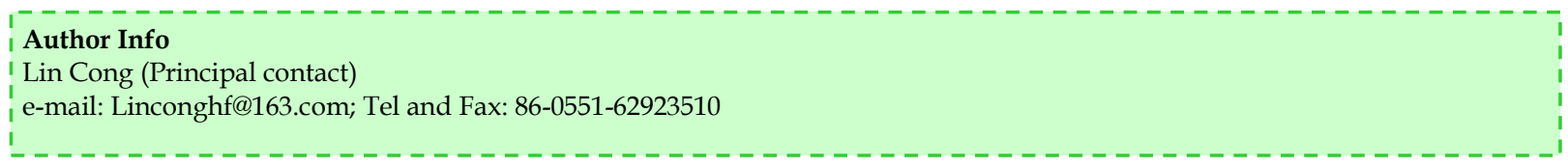




\section{Your feedback about this paper}

1. Number of times you have read this paper

2. Quality of paper

Excellent $\quad$ Good $\quad$ Moderate Not good

3. Your comments 